JOSETA: Journal of Socio Economic on Tripical Agriculture

Volume 1 Nomor 2: 10 - 19 Agustus (2019)

JOSETA: Journal of Socio Economic on Tropical Agriculture

http://joseta.faperta.unand.ac.id

ISSN : 2686 - 0953 (Online)

\title{
Analisis Implementasi Program Corporate Social Responsibility (CSR) Perusahaan Pabrik Kelapa Sawit Dalam Pengembangan Masyarakat Di Kabupaten Mandailing Natal, Sumatera Utara (Studi Kasus : PT Sago Nauli di Desa Sinunukan, Kec.Sinunukan, Kab. Mandailing Natal, Sumatera Utara)
}

Analysis of the Implementation of the Palm Oil Factory Corporate Social Responsibility (CSR) Program in Community Development in Mandailing Natal District, North Sumatra (Case Study: PT Sago Nauli in Sinunukan Village, Kec. Sinunukan, Mandailing Natal District, North Sumatra)

\author{
Suci Riswayanti ${ }^{1}$, Helmi $^{2}$, Mahdi $^{3}$ \\ ${ }^{1}$ Mahasiswa Program Studi Agribisnis Fakultas Pertanian Universitas Andalas, Padang \\ ${ }^{2}$ Staff Pengajar Program Studi Agribisnis Fakultas Pertanian Universitas Andalas, Padang \\ ${ }^{3}$ Staff Pengajar Program Studi Agribisnis Fakultas Pertanian Universitas Andalas, Padang \\ E-mail Korespondensi: sucirizwayanti21@gmail.com
}

\begin{abstract}
Abstrak
Penelitian ini bertujuan untuk menganalisis (1) Mengidentifikasi bentuk CSR yang dilaksanakan PT Sago Nauli, Mengukur persepsi masyarakat terhadap tingkat kebutuhan dan pelaksanaan CSR PT Sago Nauli. Penelitian ini dilakukan pada tanggal 26 Februari-26 Maret 2019. Data yang digunakan dalam penelitian ini adalah data primer dan data sekunder. Metode yang digunakan adalah metode studi kasus. Metode pengambilan sampel menggunakan rumus slovin sehingga sampel yang digunakan dalam penelitian berjumlah 94 KK. Data dianalisis untuk tujuan pertama dengan mendeskripsikan bentuk CSR yang dilaksanakan PT Sago Nauli, untuk tujuan kedua dianalisis menggunakan metode analisis skala likert. Hasil analisis menunjukkan (1) Bentuk program CSR yang dilaksanakan Oleh PT Sago Nauli yaitu perbaikan jalan, perbaikan sarana ibadah, peringatan hari-hari besar nasional, santunan anak yatim, dan perbaikan sarana pendidikan. (2) Persepsi masyarakat terhadap tingkat kebutuhan masyarakat sinunukan dari aspek kelembagaan, pembiayaan, social budaya masyarakat, pendidikan, dan lingkungan dinilai sangat penting. Persepsi masyarakat terhadap pelaksanaan CSR PT Sago Nauli dari aspek pendidikan dan social budaya masyarakat dinilai sangat baik sedangkan dari segi kelembagaan dan pembiayaan dinilai sangat buruk, begitu juga dari aspek lingkungan dinilai buruk.
\end{abstract}

Kata Kunci: CSR, Persepsi, Tingkat Kebutuhan 
This receach aims to analyze (1) Identify the form of CSR carried out by PT Sago Nauli, Measuring community perceptions of the level of needs and implementation of PT Sago Nauli's CSR. This research was conducted on 26 February-26 March 2019. The data used in this study were primary data and secondary data. The method used is the survey method. The sampling method uses Slovin formula so that the sample used in the study amounted to 94 families. Data were analyzed for the first purpose by describing the form of CSR carried out by PT Sago Nauli, for the second purpose analyzed using the Likert scale analysis method. The results of the analysis show (1) Forms of CSR programs implemented by PT Sago Nauli, namely road repairs, repair of religious facilities, commemoration of national holidays, compensation for orphans, and improvement of educational facilities. (2) Community perceptions of the level of community needs are from the institutional, financial, social and cultural aspects of society, education, and the environment considered very important. Public perceptions of the implementation of PT Sago Nauli's CSR from the educational and socio-cultural aspects of the community were considered to be very good while in terms of institutions and financing it was considered very bad, as well as from the environmental aspect it was considered bad.

Keywords: CSR, Perception, Requirement Level

\section{PENDAHULUAN}

Perkebunan kelapa sawit Indonesia terus mengalami perkembangan baik dari aspek luas areal maupun produksi. Luas lahan perkebunan kelapa sawit Indonesia pada 2016 diperkirakan mencapai 11,67 juta Hektare (Ha). Jumlah ini terdiri dari perkebunan rakyat seluas 4,76 juta ha, perkebunan swasta 6,15 juta HA, dan perkebunan Negara 756 ribu Ha, berdasarkan data dari Direktorat Jenderal Perkebunan Kementrian Pertanian. Sumatera Utara sendiri memiliki luas tanaman kebun kelapa sawit rakyat pada tahun 2016 sebesar 417.809 ha dengan produksi 5.775.631,82 ton tandan buah segar (TBS) (Direktorat Jenderal Perkebunan)

Pesatnya perkembangan perkebunan kelapa sawit selain memiliki dampak positif juga memiliki dampak negatif. Dampak positifnya adalah dapat meningkatkan pendapatan daerah, penyerapan tenaga kerja, disamping secara khusus dapat meningkatkan pendapatan petani dan pengusaha yang terlibat dalam agroindustri kelapa sawit. Sementara dampak negatif antara lain berpengaruh besar terhadap isu pemanasan global disebabkan karena tanaman kelapa sawit yang merupakan hutan alam monokoltur sangat boros dalam memanfaatkan air tanah sehingga keseimbangan ekologis menjadi terganggu. Adanya dampak negatif ini menjadi alasan berbagai pihak untuk menuduh bahwa perkebunan kelapa sawit sebagai salah satu penyebab pemanasan global. Dampak negatif ini hanya dapat diredam dengan pembangunan perkebunan kelapa sawit yang berkelanjutan dan berwawasan lingkungan (Saragih, 2010).

Pelaksanaan setiap kegiatan perusahaan saat ini tidak lagi hanya difokuskan pada keuntungan materi semata, namun juga telah meliputi aspek keberlanjutan lingkungan hidup seperti dalam konsep triple bottom line (profit, people, planet) yang merupakan kunci dari pelaksanaan konsep pembangunan yang berkelanjutan berbasis pengembangan masyarakat yang pada akhirnya juga akan berpengaruh pada image perusahaan di mata para stakeholders. Apabila tindakan perusahaan mempunyai dampak terhadap masyarakat tanpa adanya kompensasi apapun juga sehingga inefisiensi dalam alokasi factor produksinya terganggu, hal itu telah terjadi eksternalitas. Dalam eksternalitas itu sendiri terdapat teori yang menjadi landasannya yaitu Teorema Coase (Ronald Coase) menjelaskan bahwa apabila pihak- pihak swasta dapat melakukan tawar-menawar mengenai alokasi sumber-sumber daya tanpa harus mengeluarkan biaya, mereka dapat menyelesaikan maslah eksternalitas mereka sendirinya. Di samping 
itu juga terdapat inefesiensi, maksudnya apabila eksternalitas tidak dapat mengalokasikan sumbersumber ekonomi secara efisien sehingga munculah inefisiensi pasar.

PT. Sago Nauli merupakan pelopor perusahaan perkebunan kelapa sawit di Kabupaten Mandailing Natal yang telah berhasil melaksanakan pembangunan dan pengelolaan perkebunan kelapa sawit PIR-Trans pola kemitraan Anak Bapak Angkat. Pada tahun 1995 PT. Sago Nauli memperoleh Ijin Lokasi dari Badan Pertanahan Nasional (d/h. Kab. Tapanuli Selatan) seluas \pm 12.000 Ha yang merupakan areal bekas HPL dengan perincian \pm 9.600 Ha untuk lahan Plama dan Lahan Inti seluas \pm 2.400 Ha yang terletak di Kecamatan Sinunukan, Natal dan Batahan (d/h Kec. Batahan), Kabupaten Mandailing Natal (d/h. Tapanuli Selatan). Izin lokasi ini juga diperkuat oleh Izin Pelaksanaan Transmigrasi yang diperoleh PT. Sago Nauli pada tahun 1997.Sebagai bentuk tanggungjawab pemberdayaan penduduk asli, PT. Sago Nauli memberikan kesempatan kerja kepada penduduk desa Sinunukan dan sekitarnya untuk bekerja baik di pabrik maupun kebun PT. Sago Nauli dan terbukti dengan banyaknya putra daerah yang dipekerjakan oleh perusahaan baik sebagai operasional maupun administrasi.Selain itu perusahaan juga memberikan bantuan renovasi terhadap instansi pendidikan di daerah sekitar perusahaan. Perumusan masalah utama dalam penelitian ini adalah sampai sejauh mana PT Sago Nauli telah melakukan pengembangan masyarakat dalam implementasi CSR. Oleh sebab itu penelitian ini mengambil judul "Analisis Implementasi Program Corporate Social Responsibility (CSR) Perusahaan Pabrik Kelapa Sawit Dalam Pengembangan Masyarakat Di Kabupaten Mandailing Natal, Sumatera Utara (Studi Kasus : PT Sago Nauli di Desa Sinunukan, Kec.Sinunukan, Kab. Mandailing Natal, Sumatera Utara)"

Dari rumusan masalah utama, diturunkan beberapa pertanyaan yang lebih spesifik dalam penelitian ini, yaitu:

1. Bagaimana bentuk CSR yang dilaksanakan PT Sago Nauli?

2. Bagaimana persepsi masyarakat terhadap tingkat kebutuhan dan pelaksanaan CSR PT Sago Nauli?

\section{METODE PENELITIAN}

Penelitian ini dilakukan di Kec. Sinunukan, Kab. Mandailing Natal, Sumatera Utara. Penentuan daerah penelitian dilakukan dengan metode purposive atau sengaja. Metode penelitian yang digunakan dalam penelitian ini adalah metode studi kasus, yaitu menyoroti beberapa kasus dengan melakukan wawancara, observasi dan analisis dokumen. Metode studi kasus yang digunakan adalah bersifat deskriptif. Artinya penelitian ini dilakukan untuk menjelaskan bentuk CSR yang dilaksanakan perusahaan, mengetahui persepsi tingkat kebutuhan masyarakat dan persepsi masyarakat terhadap pelaksanaan CSR PT Sago Nauli. Dalam menganalisis data untuk tujuan pertama dengan menggambarkan bentuk CSR yang dilaksanakan PT Sago Nauli. Untuk tujuan kedua mengetahui persepsi tingkat kebutuhan masyarakat dan persepsi masyarakat terhadap pelaksanaan CSR PT Sago Nauli digunakan analisis skala likert. Skala likert menurut Sugiyono (2010:93) adalah sebagai berikut: "Skala Likert digunakan untuk mengukur sikap, pendapat dan persepsi seseorang atau sekelompok orang tentang fenomena sosial."

Kategori Pemberian Skor Alternatif Jawaban

\begin{tabular}{ccc}
\hline Alternative Jawaban & \multicolumn{2}{c}{ Skor Alternaif Jawaban } \\
\cline { 2 - 3 } & Positif & Negatif \\
\hline Sangat penting & 5 & 1 \\
\hline Penting & 4 & 2 \\
\hline Cukup penting & 3 & 3 \\
\hline Tidak penting penting & 2 & 4 \\
\hline Sangat tidak penting & 1 & 5 \\
\hline
\end{tabular}

Data yang didapatkan dilakukan editing, untuk mengecek kelengkapan pengisian kuesioner, setelah itu dilakukan coding di buku kode untuk mempermudah pengolahan data, sistem scoring dibuat konsisten yaitu semakin tinggi skor semakin tinggi kategorinya. Setelah dijumlahkan dan selanjutnya 
akan dikategorikan dengan menggunakan teknik scoring secara normatif yang dikategorikan berdasarkan interval kelas (Slamet 1993) sebagai berikut:

$$
n=\frac{M a x-\operatorname{Min}}{\sum k}
$$

Keterangan:

$\mathrm{n} \quad=$ batas selang

Max = nilai maksimum yang diperoleh dari jumlah skor

Min = nilai minimum yang diperoleh dari skor

$\sum \mathrm{k} \quad=$ jumlah kategori

Selanjutnya, tingkat persepsi berdasarkan skala Likert dijelaskan pada Tabel di bawah ini:

\begin{tabular}{cc}
\hline No & $\begin{array}{c}\text { Interval Nilai } \\
\text { Tanggapan }\end{array}$ \\
\hline $\mathbf{1}$ & $4,21-5$ \\
\hline $\mathbf{2}$ & $3,41-4,20$ \\
\hline $\mathbf{3}$ & $2,61-3,40$ \\
\hline $\mathbf{4}$ & $1,81-2,60$ \\
\hline $\mathbf{5}$ & $1,0-1,8$ \\
\hline
\end{tabular}

Tingkat Persepsi

\begin{tabular}{c}
\hline Sangat baik \\
\hline Baik \\
\hline Sedang \\
\hline Buruk \\
\hline Sangat buruk \\
\hline
\end{tabular}

\section{HASIL DAN PENELITIAN}

\section{A. Hasil Penelitian}

\section{Sejarah Ringkas PT. Sago Nauli}

PT. Sago Nauli merupakan pelopor perusahaan perkebunan kelapa sawit di Kabupaten Mandailing Natal yang telah berhasil melaksanakan pembangunan dan pengelolaan perkebunan kelapa sawit PIR- Trans pola kemitraan Anak Bapak Angkat. Pada tahun 1995 PT. Sago Nauli memperoleh Izin Lokasi dari Badan Pertanahan Nasional (d/h. Kab. Tapanuli Selatan) seluas \pm 12.000 Ha yang merupakan areal bekas HPL dengan perincian \pm 9.600 Ha untuk lahan Plama dan Lahan Inti seluas \pm 2.400 Ha yang terletak di Kecamatan Sinunukan, Natal dan Batahan (d/h Kec. Batahan), Kabupaten Mandailing Natal (d/h. Tapanuli Selatan). Izin lokasi ini juga diperkuat oleh Izin Pelaksanaan Transmigrasi yang diperoleh PT. Sago Nauli pada tahun 1997.

\section{Gambaran Umum Sinunukan}

Letak dan Geografis Kecamatan Sinunukan
Luas Wilayah
: 236, $63 \mathrm{KM}^{2}$
Ketinggian di atas Permukaan Laut $\quad: 200-300$ Meter
Batas Wilayah
Sebelah Utara
: Kecamatan Natal
Sebelah Selatan
: Prov. Sumatera Barat
Sebelah Barat
: Kecamatan Batahan
Sebelah Timur
: Kecamatan Lingga Bayu, Kecamatan Ranto Baek

Terdapat beberapa daerah dampak CSR PT Sago Nauli yaitu Sinunukan II, Sinunukan III, Sinunukan IV, dan Pasir Putih.

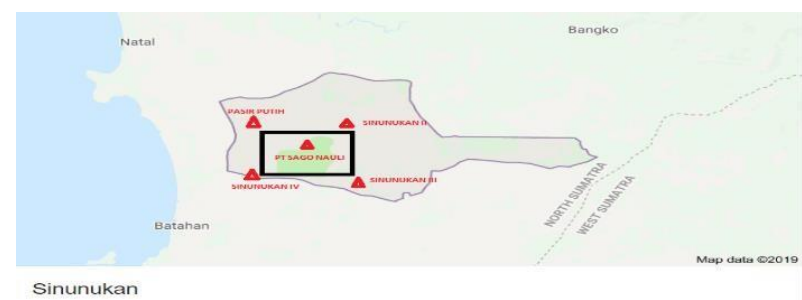




\section{Bentuk CSR PT Sago Nauli}

PT Sago Nauli telah melaksanakan program Corporate Social Responsibility (CSR) yaitu :

a. Perbaikan Jalan

Sinunukan merupakan salah satu kecamatan di Mandailing Natal. Sebagai daerah transmigrasi yang dibuka tahun 1980-an, keadaaan jalan Sinunukan masih tergolong tanah dan bebatuan. Ada beberapa jalan yang sudah beraspal disepanjang jalan lintas Sinunukan III dengan ukuran panjang sekitar 5 KM. Selain itu lebih dari 120 KM jalan Sinunukan masih berupa tanah dan bebatuan. Tekstur jalan tanah sangat memiliki resiko tinggi ketika musim hujan datang. Hal yang sering terjadi yaitu jalan mejadi rusak dan sulit untuk dilewati kendaraan. Hal ini menjadi salah satu hambatan serta masalah yang sering terjadi di daerah Sinunukan. Bentuk tanggung jawab yang dilaksanakan perusahaan yaitu dengan memfasilitasi perbaikan jalan di setiap desa dampak perusahaan yaitu dengan meluncurkan alat- alat berat perbaikan jalan. Perbaikan jalan ini merupakan hal rutin yang dilaksanakan oleh perusahaan. Desa yang telah rutin mendapat perbaikan jalan yaitu Sinunukan II, Sinunukan III, Sinunukan IV, dan Pasir Putih

b. Perbaikan Sarana Ibadah (Masjid)

Sebagai umat manusia selayaknya menjadi hamba yang taat terhadap Tuhan Yang Maha Esa. Sarana ibadah yang mendukung menjadi salah satu cara meningkatkan kenyamanan dalam melaksanakan ibadah. Masjid merupakan tempat ibadah umat Islam, sebagai sarana ibadah tentu harus memperhatikan kenyamanan bagi masyarakat. Bentuk kepedulian yang disumbangsihkan perusahaan kepada masyarakat sekitar yaitu memberikan bantuan berupa bantuan biaya untuk perbaikan atau renovasi Masjid. Bantuan diberikan kepada pengurus masjid berupa uang tunai sebesar Rp 9.500.000 kepada pengurus Masjid Al Ma'ruf Desa Sinunukan III.

c. Peringatan Hari-Hari Besar Nasional

Peringatan hari kemerdekan RI yang dilaksanakan di kecamatan Sinunukan yaitu melaksanakan upacara peringatan hari kemerdekaan juga dibaregi dengan kegiatan festival budaya setempat juga melaksanakan kegiatan perlombaan dalam bidang akademik. Dalam pelaksanaan tersebut sengaja dirancang panitia yang bertanggung jawab demi kelancaran selama acara. Dengaan demikian bentuk kepedulian dan tanggung jawab perusahaan terhadap masyarakat yaitu dengan memberikan bantuan fisik berupa bantuan dana dalam mendukung terlaksanaanya acara. Bentuk bantuan yang diberikan yaitu berupa uang tunai sebesar Rp 5.500.000,- .

\section{d. Santunan Kepada Anak Yatim dan Lansia}

Bentuk tanggung jawab sosial yang dilaksanakan oleh perusahaan yaitu memberikan santunan kepada anak yatim dan juga lansia yaitu sebanyak 41 anak yatim dan 20 orang lansia dari desa Sinunukan IV dan Pasir Putih. Kegiatan ini dilaksanakan setiap setahun sekali pada bulan ramadhan menjelang hari raya Idul Fitri. Dana yang kemudian dibagikan sebagai santunan itu berasal dari penghimpunan infak ikhlas yaitu berasal dari jamaah masjid, warga PMKS dan karyawan yang terkumpul sebanyak Rp 8.000.000,- dan juga dari PT. Sago Nauli sebanyak angka yang sama yaitu Rp 8.000.000,--

\section{e. Perbaikan Sarana Pendidikan}

Perbaikan sarana pendidikan yang dilakukan oleh perusahaan yaitu memberikan bantuan berupa kursi, meja, pagar sekolah, dan perbaikan lainnya. Perbaikan ini tidak hanya di sekolah-sekolah melainkan di Madrasah Aliyah. Selain perbaikan sarana sekolah, perusahaan juga menyediakan bus sekolah.

\section{Renovasi Gedung Madrasah Miftahul Huda Sinunukan IV}

Panitia pembangunan gedung madrasah Miftahul Huda Sinunukan IV, membuktikan kesungguhan dalam melaksanakan amanah dari PT. Sago Nauli berupa bantuan sebesar Rp 29.200.000,- 
untuk renovasi ruang belajar madrasah. Melalui kepala desa Sinunukan IV, Triyatno, mereka menunjukkan hasil renovasi madrasah sebagai berikut : (2015-01-28)

\section{Bantuan Kursi untuk Madrasyah Diniyah Desa Sukadamai}

PT. Sago Nauli yang melalui program CSR-nya telah beberapa kali memberikan bantuan pada perkembangan dan peningkatan kualitas pendidikan di kawasan seputar Sinunukan. Melihat adanya kebutuhan sarana belajar bagi siswa madrasah di Sukadamai, PT. Sago Nauli tergerak untuk turut berpartisipasi. Bantuan berupa 60 buah kursi kayu pun disiapkan dan diserahkan pada jumat (24/10/2014). Penyerahan dilakukan oleh Biro Artha, Ibu MR Pasaribu dan anggota Humas, Dedi mewakili PT. Sago Nauli yang diterima oleh Kepala Desa Sukadamai, Bapak Syamsuddin Nasution.

\section{Bantuan untuk MDA Nurul Huda Sinunukan II}

Selanjutnya lembaga pendidikan yang menerima bantuan dari PT Sago Nauli adalah Madrasah Diniyah Awaliyah (MDA) Nurul Huda Desa Sinunukan II. Bantuan sebesar Rp 30.000.000,- tersebut diberikan memenuhi permohonan yang diajukan pihak yayasan Nurul Huda yang diketahui Kepala Desa Sinunukan II. Penyerahan bantuan dilakukan pada Kamis (18/12/2014) oleh Ir. Khairun Nur (Manager Plasma I-II) yang mewakili PT. Sago Nauli dan diterima oleh pengelola MDA Nurul Huda disaksikan kepala desa Sinunukan II.

\section{Bantuan Pembangunan Pagar Sekolah}

Bantuan lain diberikan kepada SD Negeri 331 Desa Pasir Putih. Tidak sebagaimana untuk Nurul Huda, bantuan untuk SD Negeri 331 bukan berupa dana tunai, melainkan pembangunan pagar sekolah. PT. Sago Nauli yang membangun pagar dan setelah selesai diserahkan kepada pihak sekolah. Penyerahan pagar yang telah selesai dibangun dengan menghabiskan dana sebesar Rp 28.951.200,tersebut dilakukan oleh Manager Inti, Ir. Imam Santoso atas nama management PT. Sago Nauli, dan diterima dengan baik oleh Ibu Maryati, Kepala SD Negeri 331 Pasir Putih.

\section{Bus Sekolah}

Selain perbaikan sarana pendidikan, PT Sago Nauli juga menyediakan bus sekolah. Bus sekolah ini dikhususkan untuk daerah yang jarak lokasi cukup jauh ke sekolah lanjutan, yaitu di desa Pasir Putih. Bus yang disediakan yaitu dengan kapasitas 30 orang. Segala operasional bus termasuk biaya BBM, supir dan perawatan supir disediakan oleh perusahaan. Bus beroperasi mulai pukul $07.00-15.00$ WIB. Bus ini sangat membantu siswa yang tidak memiliki kendaraan untuk menuju ke sekolah.

\section{Analisis Persepsi Tingkat Kebutuhan Masyarakat dan Pelaksanaan CSR PT Sago Nauli}

Analisis persepsi tingkat kebutuhan masyarakat dan pelaksanaan CSR PT Sago Nauli dilihat dari indikator kelembagaan, Pembiayaan, Sosial Budaya Masyarakat, Pendidikan, dan Lingkungan. Masing-masing komponen terdiri dari beberapa pertanyaan yang menggambarkan tingkat kebutuhan masyarakat Sinunukan.

Tabel 1. Persepsi terhadap Indikator Kelembagaan

\begin{tabular}{clcccc}
\hline \multirow{2}{*}{ No Indikator Kelembagaan } & \multicolumn{2}{c}{ Tingkat Kebutuhan } & \multicolumn{2}{c}{ Pelaksanaan CSR } \\
\cline { 3 - 6 } & $\begin{array}{c}\text { Skor } \\
\text { Rataan }\end{array}$ & Keterangan & $\begin{array}{c}\text { Skor } \\
\text { Rataan }\end{array}$ & Keterangan \\
\hline 1 & $\begin{array}{l}\text { Adanya lembaga di tingkat local yang mengelola } \\
\text { program dan kegiatan (mulai dari perencanaan } \\
\text { Sampai evaluasi) }\end{array}$ & 4,9 & Sangat Penting & 1,6 & Sangat Buruk \\
2 & $\begin{array}{l}\text { Lembaga local merupakan perwakilan dari } \\
\text { berbagai kelompok masyarakat yang dipilih } \\
\text { secara musyawarah }\end{array}$ & 4,9 & Sangat Penting & 1,6 & Sangat Buruk \\
3 & $\begin{array}{l}\text { Lembaga local merupakan lembaga masyarakat } \\
\text { yang mampu menampung aspirasi masyaraakat }\end{array}$ & 4,8 & Sangat Penting & 1,6 & Sangat Buruk \\
4 & $\begin{array}{l}\text { Lembaga local merupakan lemabga masyarakat } \\
\text { yang mampu memperjuangkan aspirasi } \\
\text { masyarakat ke pihak lain di luar }\end{array}$ & 4,9 & Sangat Penting & 1,6 & Sangat Buruk \\
\hline Total & 4,9 & Sangat Penting & 1,6 & Sangat Buruk \\
\hline
\end{tabular}




\begin{tabular}{|c|c|c|c|c|c|}
\hline \multirow[b]{2}{*}{ No } & \multirow[b]{2}{*}{ Indikator Pembiayaan } & \multicolumn{2}{|c|}{ Tingkat Kebutuhan } & \multicolumn{2}{|c|}{ Pelaksanaan CSR } \\
\hline & & $\begin{array}{l}\text { Skor } \\
\text { Rataan }\end{array}$ & Keterangan & $\begin{array}{l}\text { Skor } \\
\text { Rataan }\end{array}$ & Keterangan \\
\hline 1 & $\begin{array}{l}\text { Adanya lembaga di tingkat local yang mengelola } \\
\text { keuangan }\end{array}$ & 4,1 & Penting & 1,4 & Sangat Buruk \\
\hline 2 & $\begin{array}{l}\text { Kegiatan dana bergulir untuk pengembangan } \\
\text { usaha ekonomi masyarakat }\end{array}$ & 4,9 & Sangat Penting & 1,4 & Sangat Buruk \\
\hline 3 & Peminjaman tanpa agunan (jaminan) & 4,7 & Sangat Penting & 1,2 & Sangat Buruk \\
\hline 4 & $\begin{array}{l}\text { Sistem bagi hasil antara pengelola pinjaman } \\
\text { dengan peminjam }\end{array}$ & 4,6 & Sangat Penting & 1,3 & Sangat Buruk \\
\hline & Total & 4,6 & Sangat Penting & 1,3 & Sangat Buruk \\
\hline
\end{tabular}

Tabel 3. Persepsi terhadap Indikator Sosial Budaya Masyarakat

\begin{tabular}{llccccc}
\hline \multirow{2}{*}{ No } & \multicolumn{2}{c}{ Indikator Sosial Budaya masyarakat } & \multicolumn{2}{c}{ Tingkat Kebutuhan } & \multicolumn{2}{c}{ Pelaksanaan CSR } \\
\cline { 3 - 6 } & $\begin{array}{c}\text { Skor } \\
\text { Rataan }\end{array}$ & Keterangan & $\begin{array}{c}\text { Skor } \\
\text { Rataan }\end{array}$ & Keterangan \\
\hline 1 & $\begin{array}{l}\text { Adanya kegiatan yang menggali dan mengelola } \\
\text { potensi budaya setempat (Taman Budaya, } \\
\text { Sanggar Desa) }\end{array}$ & 3,9 & Penting & 2,0 & Buruk \\
2 & $\begin{array}{l}\text { Rasa saling percaya dan gotong royong sebagai } \\
\text { kekuatan masyarakat }\end{array}$ & 5,0 & Sangat Penting & 4,6 & Sangat Baik \\
3 & $\begin{array}{l}\text { Partisipasi masyarakat dalam seluruh tahapan } \\
\text { kegiatan }\end{array}$ & 4,9 & Sangat Penting & 4,9 & Sangat Baik \\
$\begin{array}{l}\text { Perhatian terhadap kelompok warga kurang } \\
\text { mampu, berkebutuhan khusus, dan kelompok } \\
\text { warga yang memerlukan perhatian khusus } \\
\text { lainnya) }\end{array}$ & 4,9 & Sangat Penting & 4,7 & Sangat Baik \\
\hline
\end{tabular}

Tabel 4. Persepsi terhadap Indikator Pendidikan

\begin{tabular}{llcccc}
\hline \multirow{2}{*}{ No } & \multirow{2}{*}{ Indikator Pendidikan } & \multicolumn{2}{c}{ Tingkat Kebutuhan } & \multicolumn{2}{c}{ Pelaksanaan CSR } \\
\cline { 3 - 6 } & & $\begin{array}{c}\text { Skor } \\
\text { Rataan }\end{array}$ & Keterangan & Skor & Keterangan \\
Rataan & \\
\hline 1 & Adanya beasiswa masuk Perguruan Tinggi & 4,8 & Sangat Penting & 3,9 & Baik \\
2 & Perbaikan prasarana tempat pendidikan & 4,9 & Sangat Penting & 4,8 & Sangat Baik \\
3 & Fasilitas transportasi bus sekolah & 4,7 & Sangat Penting & 4,9 & Sangat Baik \\
4 & Adanya fasilitas ibadah (masjid,gereja, kuil, dll) & 4,9 & Sangat Penting & 4,9 & Sangat Baik \\
5 & Kegiatan peringatan hari-hari Besar Nasional & 4,8 & Sangat Penting & 4,9 & Sangat Baik \\
\hline \multirow{2}{*}{ Total } & 4,8 & Sangat Penting & 4,7 & Sangat Baik \\
\hline
\end{tabular}




\begin{tabular}{clcccc}
\hline \multirow{2}{*}{ No } & \multicolumn{2}{c}{ Indikator Lingkungan } & \multicolumn{2}{c}{ Tingkat Kebutuhan } & \multicolumn{2}{c}{ Pelaksanaan CSR } \\
& & $\begin{array}{c}\text { Skor } \\
\text { Rataan }\end{array}$ & Keterangan & $\begin{array}{c}\text { Skor } \\
\text { Rataan }\end{array}$ & Keterangan \\
\hline 1 & Pemanfaatan limbah untuk usaha produktif & 3,9 & Sangat Penting & 1,4 & Sangat Buruk \\
2 & $\begin{array}{l}\text { Edukasi untuk masyarakat tentang pengelolaan } \\
\text { limbah }\end{array}$ & 3,8 & Sangat Penting & 1,4 & Sangat Buruk \\
3 & $\begin{array}{l}\text { Masyarakat berpartisipasi aktif dalam menjaga } \\
\text { kelestarian alam dan lingkungan }\end{array}$ & 5,0 & Sangat Penting & 4,1 & Baik \\
4 & $\begin{array}{l}\text { Pengelolaan limbah dan sampah secara } \\
\text { berkelanjutan }\end{array}$ & 4,2 & Sangat Penting & 1,2 & Sangat Buruk \\
\hline & Total & 4,2 & Sangat Penting & 2,0 & Buruk \\
\hline
\end{tabular}

\section{B. Pembahasan}

Penelitian memiliki dua tujuan utama yaitu mengetahui bentuk CSR yang dilaksanakan oleh PT Sago Nauli, kemudian tujuan kedua yaitu untuk mengetahui persepsi masyarakat mengenai tingkat kebutuhan masyarakat Sinunukan serta persepsi masyarakat terhadap pelaksanaan CSR PT Sago Nauli. Untuk tujuan pertama dapat dilihat bahwa bentuk CSR yang dilaksanakan oleh PT Sago Nauli yaitu perbaikan sarana umum, perbaikan sarana ibadah, perbaikan saran pendidikan, peringatan hari-hari besar dan santunan kepada anak yatim piatu dan lansia..

Hal yang terjadi yaitu masyarakat secara jelas kurang memahami bagaimana pelaksanaan CSR yang semestinya. Hal tersebut juga disampaikan oleh Kepala Desa Sinunukan III,.Begitu pula pihak PT Sago Nauli tidak memberikan pengetahuan kepada masyarakat mengenai CSR. Bentuk CSR yang dilaksanakan hingga saat ini hanya perangkat-perangkat desa yang berpartisipasi dalam pelaksanaannya. Pasalnya PT Sago Nauli tidak menjelaskan serta mensosialisasikan program CSR kepada masyarakat, sehingga masyarakat yang awalnya tidak memahami apa itu CSR juga tidak berpartisipasi aktif dalam pelaksanaannya.

Dalam praktiknya, program CSR umumnya lebih bersifat karitatif (charity) (Suparlan, 2005:12 dan Sugihen, 2006 dalam Afifah, Dzul, 2011) umumnya kurang atau tidak bersifat mendidik sasaran. Hal ini berakibat sasaran menjadi tergantung atau memiliki ketergantungan kepada pihak lain. Pelaksanaan CSR belum memikirkan sasaran untuk mau berubah perilakunya (pengetahuan, keterampilan dan sikap) agar mereka mampu menolong dirinya sendiri. Sago Nauli saat ini hanya memberikan bantuan material atau bantuan langsung tunai kepada masyarakat tanpa dibarengi proses sosialisasi, bimbingan atau pelatihan yang dapat mengubah perilaku masyarakat sehingga masyarakat dapat mandiri dan tidak bergantung pada pihak lain. Bantuan yang berupa bantuan fisik, fasilitas pendidikan, keagamaan, dan sebagainya lebih bersifat top down, dan kurang memperhatikan aspirasi masyarakat. Dengan kata lain implementasi CSR belum memperhatikan aspek kebutuhan masyarakat atau belum didasarkan pada need assessment

Untuk tujuan kedua yaitu persepsi tingkat kebutuhan masyarakat dengan indicator kelembagaan lokal, pembiayaan, social budaya, pendidikan, dan lingkungan dinilai sangat penting. Untuk indicator kelembagaan lokal dinilai sangat penting oleh masyarakat sebagai lembaga masyarakat yang mampu memperjuangkan aspirasi masyarakat sebagai upaya pengembangan masyarakat lokal. Pengembangan masyarakat merupakan suatu kegiatan sosial yang bekerja dengan komunitas dan melibatkan partisipasi aktif dari komunitas lokal dalam memenuhi kebutuhan dan menyelesaikan masalah-masalah yang ada dalam komunitas itu sendiri dengan menggunakan sumber-sumber yang tersedia didalamnya (Hasim dan Remiswal 2009 dalam Asriani, Meilisa. 2014).

Selanjutnya tingkat kebutuhan masyarakat Sinunukan dalam bidang pembiayaan dinilai sangat penting, terlihat pada setiap indicator yang dinilai. Pembiayaan yang sangat dibutuhkan oleh masyarakat Sinunukan yaitu adanya dana bergulir untuk pengembanagan usaha ekonomi masyarakat. Namun dalam penelitian yang dilakukan oleh Sumaryo (2009) mengenai "Implementasi Tanggungjawab Sosial Perusahaan (Corporate Social Responsibility) dalam Pemberdayaan dan Peningkatan Kesejahteraan 
Masyarakat: Kasus di Provinsi Lampung" menunjukkan bahwa pemberdayaan masyarakat dalam bidang ekonomi tidak cukup hanya dengan pemberian modal bergulir, tetapi juga harus ada penguatan kelembagaan ekonomi masyarakat, penguatan sumberdaya manusianya, penyediaan prasarananya, penguatan posisi tawarnya, pemberdayaan masyarakat dalam bidang ekonomi atau penguatan ekonomi rakyat harus dilakukan secara elegan tanpa menghambat dan mendiskriminasikan ekonomi kuat, untuk itu kemitraan antar usaha mikro, usaha kecil, usaha menengah, dan usaha besar adalah jalan yang harus ditempuh.

Tingkat kebutuhan masyarakat bidang social budaya dinilai sangat penting, terlihat pada indicator rasa saling percaya dan gotong royong sebagai kekuatan masyarakat dengan kategori sempurna $(5,0)$. Rasa saling percaya sangat dibutuhkan oleh masyarakat. Ketika masyarakat memiliki rasa saling percaya maka tingkat partisipasi masyarakat juga akan semakin tinggi. Keterlibatan atau keikutsertaan masyarakat dalam setiap kegiatan merupakan factor pendukung penting. Peran serta masyarakat tertinggi adalah peran serta yang yang benar-benar memberikan otoritas pada komunitas atau masyarakat (Arstein, 1969 dalam Agustin, 2013).

Kebutuhan masyarakat dalam bidang pendidikan juga dinilai sangat penting. Pendidikan merupakan usaha sadar untuk menyumbangkan kemampuan usaha manusia dalam rangka memajukan aktivitas. Pendidikan sebagai suatu aspek yang menyumbangkan sumber daya manusia yang dimaksudkan untuk meningkatkan pengetahuan dan kemampuan seseorang dalam berbagai kegiatan, juga diharapkan mampu membuka cara berpikir ekonomis dalam arti mampu mengembangkan potensi yang ada untuk memperoleh hasil semaksimal mungkin. Hal ini juga didukung oleh (Tarigan, 2006 dalam Saefihim, 2014) yang menyatakan bahwa Pendidikan diyakini sangat berpengaruh terhadap kecakapan, tingkah laku dan sikap seseorang, dan hal ini semestinya terkait dengan tingkat pandapatan seseorang. Artinya secara rata-rata makin tinggi tingkat pendidikan seseorang maka makin memungkinkan orang tersebut memperoleh pendapatan yang lebih tinggi. Selain itu, pendidikan memang sangat diperlukan dan berguna bagi anggota masyarakat. Pendidikan sebenarnya bukan hanya terkait dengan kemampuan untuk memperoleh tingkat pendapatan yang lebih baik tapi juga berpengaruh terhadap sikap dan perilaku sehingga terkait dengan kehidupan sehari-hari.

Kemudian tingkat kebutuhan masyarakat dalam aspek lingkungan juga dinilai sangat penting, terlihat pada indicator masyarakat berpartisipasi aktif dalam menjaga kelestarian alam dan lingkungan. Keberlanjutan ekologis adalah prasyarat untuk pembangunan dan keberlanjutan kehidupan. Keberlanjutan ekologis akan menjamin keberlanjutan ekosistem bumi.

Selanjutnya persepsi masyarakat terhadap pelaksanaan CSR PT Sago Nauli dari aspek kelembagaan lokal dan pembiayaan dinilai sangat buruk sedangkan dalam aspek pendidikan dinilai sangat baik begitu juga dengan aspek siosial budaya dinilai baik dalam pelaksanaannya. Namun dalam aspek lingkungan masih dinilai buruk dalam pelaksanaannya. Sebagai bentuk tanggung jawab social atas kegiatan usaha yang dilakukan perusahaan terhadap masyarakat dampak sekitar, CSR PT Sago Nauli dalam pelaksanaannya masih tergolong charity yaitu dalam umumnya kurang atau tidak bersifat mendidik sasaran (Suparlan, 2005:12 dan Sugihen, 2006 dalam Afifah, Dzul. 2011).

Dalam pelaksanaannya belum adanya lembaga lokal yang sengaja dibentuk oleh pihak perusahaan sebagai lembaga khusus yang menangani CSR di setiap desa. Sehingga dalam penyalurannya CSR yang diberikan hanya akan melalui perangkat desa yaitu melalui Kepala Desa setempat dengan mengajukan proposal kegiatan yang dicanangkan. Dalam pelaksanaannya masyarakat tidak diberikan keleluasan dalam berpartisipasi dalam menentukan perencanaan sekaligus pelaksanaaannya. Kelembagaan lokal yang dibentuk dengan harapan mampu menjadi wadah yang mampu memperjuangkan aspirasi masyarakat. Sehingga kegiatan CSR yang dilaksanakan sesuai de ngan kebutuhan masyarakat.

Begitu juga dalam pelaksanaan bidang pembiayaan masih dinilai sangat buruk, pasalnya perusahaan belum melaksanakan kegiatan dalam pembiayaan seperti adanya dana bergulir untuk pengembangan usaha ekonomi masyarakat serta pinjaman tanpa agunan. Berbeda dengan aspek kelembagaan lokal dan pembiayaan, persepsi masyarakat terhadap pelaksanaan CSR Sago nauli dalam aspek social budaya dinilai buruk. Dalam pelaksanaannya perusahaan memang tidak memberikan wadah untuk masyarakat dalam melestarikan budaya setempat, namun perusahaan memberikan perhatian kepada kelompok warga kurang mampu dan berkebutuhan khusus. 
Kemudian dalam aspek pendidikan, pelaksanaan CSR Sago Nauli dinilai sangat baik. Menurut (Drijarkara, 2001 dalam Saefihim, 2014) pendidikan adalah memanusiakan manusia. Pelaksanaan pendidikan berlangsung dalam keluarga sebagai pendidikan informal, di sekolah sebagai pendidikan formal, dan di masyarakat sebagai pendidikan nonformal serta berlangsung seumur hidup. Upaya yang dilakukan oleh perusahaan yaitu dengan memberikan bantuan perbaikan sarana pendidikan juga memberikan beasiswa untuk calon siswa masuk perguruan tinggi. Terlihat bahwa perusahaan peduli akan pentingnya pendidikan bagi setiap orang. Harapannya pihak perusahaan terus memberikan tanggung jawabnya sesuai dengan kebutuhan masyarakat.

\section{PENUTUP}

A. Kesimpulan

Berdasarkan penelitian yang dilakukan maka dapat diperoleh kesimpulan yaitu :

1. Bentuk program CSR yang dilaksanakan Oleh PT Sago Nauli yaitu perbaikan jalan, perbaikan sarana ibadah, peringatan hari-hari besar nasional, santunan anak yatim, dan perbaikan sarana pendidikan. Persepsi masyarakat terhadap tingkat kebutuhan masyarakat sinunukan dari aspek kelembagaan, pembiayaan, social budaya masyarakat, pendidikan, dan lingkungan dinilai sangat penting.

2. Persepsi masyarakat terhadap pelaksanaan CSR PT Sago Nauli dari aspek pendidikan dan social budaya masyarakat dinilai sangat baik sedangkan dari segi kelembagaan dan pembiayaan dinilai sangat buruk, begitu juga dari aspek lingkungan dinilai buruk.

B. Saran

Berdasarkan hasil penelitian yang telah dilaksanakan, adapun saran yang diberikan yaitu agar pihak perusahaan mengikutsertakan masyarakat dalam segala kegiatan program CSR yang dilaksanakan dimulai dari perencanaan hingga pelaksanaan/evaluasi. Dalam pelaksanaannya perusahaan juga harus memperhatikan tingkat kebutuhan masyarakat program CSR yang dilaksanakan tepat sasaran dan tujuan. Begitu pula dengan pemerintah Daerah agar melakukan pengawasan terhadap pelaksanaan CSR yang dilaksanakan oleh prusahaan yang bersangkutan.

\section{DAFTAR PUSTAKA}

Afifah, Dzul. 2011. Persepsi Dan Partisipasi Masyarakat Terhadap Kegiatan Corporate Social Responsibility (Csr) Oleh PT. Wirakarya Sakti Dalam Penguatan Ekonomi Lokal. [skripsi]. Departemen Sains Komunikasi dan Pengembangan Masyarakat. Fakultas Ekologi Manusia. Institut Pertanian Bogor.

Agustin. 2013. Keefektifan Pelayanan Tanggungjawab Sosial Perusahaan Sebagai Upaya Peningkatan Kualitas Sumberdaya Manusia. [skripsi]. Departemen Sains Komunikasi dan Pengembangan Masyarakat. Fakultas Ekologi Manusia. Institut Pertanian Bogor.

Asriani, Meilisa. 2014. Pengembangan Masyarakat Melalui Program Kredit Mikro Dalam Tanggung Jawab Sosial Perusahaan PT South Pasific Viscose. [skripsi]. Departemen Sains Komunikasi dan Pengembangan Masyarakat. Fakultas Ekologi Manusia. Institut Pertanian Bogor.

Saefihim. 2014. Analisis Manfaat Program Corporate Social Responsibility (Csr) Terhadap Tingkat Pendidikan Masyarakat Desa Sekitar Perusahaan. [skripsi]. Departemen Sains Komunikasi dan Pengembangan Masyarakat. Fakultas Ekologi Manusia. Institut Pertanian Bogor.

Sumaryo. 2009. Implementasi Tanggungjawab Perusahaan (Corporate Social Responsibility) Dalam Pemberdayaan Dan Peningkatan Kesejahteraan Masyarakat ; Kasus Di Provinsi Lampung. ). [skripsi]. Departemen Sains Komunikasi dan Pengembangan Masyarakat. Fakultas Ekologi Manusia. Institut Pertanian Bogor. 